\title{
PKM Pelatihan Pembuatan Artikel Ilmiah Dari Hasil Skripsi Dan Cara Mempublish Di Jurnal Pada Mahasiswa STIE LMII
}

\author{
${ }^{1)}$ Nera Mayana Br Tarigan, ${ }^{2)}$ Ricky Martin Ginting, ${ }^{3)}$ Santa Elisa Br Tarigan \\ ${ }^{1,2,3,4)}$ Teknik Informatika, STMIK Pelita Nusantara \\ Email: ${ }^{1}$ neramayana658@gmail.com
}

\begin{tabular}{ll}
\hline INFORMASI ARTIKEL & ABS TRA K \\
\hline Kata Kunci: & Hasil penelitian mahasiswa (skripsi) sudah seharusnya dipublikasikan baik \\
Pelatihan & berupa repositori perguruan tinggi maupun pada jurnal ilmiah. Sesuai dengan \\
Pembuatan & surat edaran Direktorat Jenderal Pembelajaran Dan Kemahasiswaan Nomor: \\
Publish & B/565/B.B1/HK.01.01/2019 pada tanggal 8 Juli 2019 tentang Sarana \\
Artikel Ilmiah & Publikasi Karya Ilmiah Mahasiswa. STIE LMII merupakan instansi \\
& pendidikan tinggi yang menghasilkan lulusan dengan melakukan penelitian \\
& sebagai syarat untuk dinyatakan lulus menjadi seorang sarjana manajemen. \\
& Namun dengan surat edaran yang disebutkan diatas maka mahasiswa STIE \\
& LMII masih bingung untuk melakukan publikasi karya ilmiah dari hasil \\
& skripsinya. Baik dari segi pembuatan artikel ilmiah dari hasil skripsinya \\
& maupun cara mempublikasikannya pada jurnal ilmiah. Maka dari permasalah \\
& ini tim pengabdian kepada masyarakat bertujuan untuk melakukan pelatihan \\
& pembuatan artikel ilmiah dari hasil penelitian/skripsi mahasiswa dan \\
& pelatihan cara mempublish artikel ilmiah pada jurnal ilmiah. Bahwa \\
& mahasiswa STIE LMII sangat tertarik dan yang mengikuti pelatihan sangat \\
& mudah mengikuti materi pelatihan Mahasiswa STIE LMII yang mengikuti \\
& pelatihan mampu membuat artike ilmiah dari hasil penelitian/skripsi.
\end{tabular}

\section{ABSTRACT}

Keywords:

Training

Creation

Publish

Scientific Articles
The results of student research (thesis) have been achieved both in the form of university repositories and in scientific journals. In accordance with the circular letter of the Directorate General of Learning and Student Affairs Number: B/565/B.B1/HK.01.01/2019 on July 8, 2019, concerning Facilities for Publication of Student Scientific Work. STIE LMII is a higher education institution that produces graduates by conducting research as a requirement to graduate as a management graduate. However, with the circular mentioned above, STIE LMII students are still confused about publishing scientific papers from the results of their thesis. Both in terms of making scientific articles from the results of their thesis and how they are published in scientific journals. So from this problem the community service team aims to conduct training in making scientific articles from the results of student research/thesis and training on how to publish scientific articles in scientific journals. That STIE LMII students are very interested and participate in the training easily following the material. STIE LMII students who take part in the training make scientific articles from the results of the research/thesis.

This is an open access article under the CC-BY-SA license.

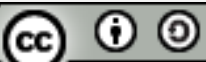




\section{PENDAHULUAN}

Tugas akhir atau sering disebut skripsi mahasiswa merupahan hasil penelitian mahasiswa yang dibimbing oleh dosen pembimbing. Hasil penelitian mahasiswa ini sudah seharusnya dipublikasikan baik berupa repositori perguruan tinggi maupun pada jurnal ilmiah. Sesuai dengan surat edaran Direktorat Jenderal Pembelajaran Dan Kemahasiswaan Nomor : B/565/B.B1/HK.01.01/2019 pada tanggal 8 Juli 2019 tentang Sarana Publikasi Karya Ilmiah Mahasiswa.

STIE LMII merupakan instansi pendidikan tinggi yang menghasilkan lulusan dengan melakukan penelitian sebagai syarat untuk dinyatakan lulus menjadi seorang sarjana manajemen. Namun dengan surat edaran yang disebutkan diatas maka mahasiswa STIE LMII masih bingung untuk melakukan publikasi karya ilmiah dari hasil skripsinya. Baik dari segi pembuatan artikel ilmiah dari hasil skripsinya maupun cara mempublikasikannya pada jurnal ilmiah.

Jurnal ilmiah adalah sebuah publikasi yang diterbitkan secara berkala oleh suatu organisasi profesi atau institusi akademik yang memuat artikel- artikel yang merupakan produk pemikiran ilmiah secara empiris (artikel hasil penelitian) maupun secara logis (artikel hasil pemikiran) dalam bidang ilmu tertentu.

Untuk dapat diterima artikel ilmiah yang akan dipublish pada jurnal yang dituju, maka peneliti/penulis harus mengikuti gaya penulisan atau template yang sudah disediakan dan bidang ilmu apa yang dapat diterima pada jurnal tersebut.

Sesuai dengan uraian analisa situasi diatas maka tim pengabdian kepada masyarakat dalam proposal ini akan melakukan pelatihan bagaimana cara merubah hasil penelitian skripsi menjadi artikel ilmiah dan juga melatih bagaimana cara untuk mempublishnya pada jurnal ilmiah.

Semoga dengan diadakannya pengabdian kepada masyarakat atau pelatihan ini mahasiswa STIE LMII yang sudah melaksanakan ujian skrips/UMH dan dinyatakan lulus dapat memahami dan mampu mengubah hasil penelitian/skripsinya dalam bentuk artikel ilmiah dan juga mampu mempublishnya pada jurnal ilmiah.

Dengan pengamatan yang dilakukan tim bahwa mahasiswa STIE LMII yang akan sudah melaksanakan ujian skripsi/UMH masih bingung dan tidak tahu bagaimana cara untuk membuar artikel ilmiah dari hasil skripsinya dan bagaimana cara mempublishnya ke jurnal ilmiah. Dari uraian tersebut maka ditarik rumusan masalah yaitu "bagaimana melakukan pelatihan pembuatan artikel ilmiah dari hasil skripsi dan mempublikasikannya"?

\section{MASALAH}

Dengan pengamatan yang dilakukan tim bahwa mahasiswa STIE LMII yang akan sudah melaksanakan ujian skripsi/UMH masih bingung dan tidak tahu bagaimana cara untuk membuar artikel ilmiah dari hasil skripsinya dan bagaimana cara mempublishnya ke jurnal ilmiah. Dari uraian tersebut maka ditarik rumusan masalah yaitu "bagaimana melakukan pelatihan pembuatan artikel ilmiah dari hasil skripsi dan mempublikasikannya"?

\section{METODE}

Menggambarkan jumlah responden serta mengambarkan metode dan proses jalannya pengabdian yang dilaksanakan. 


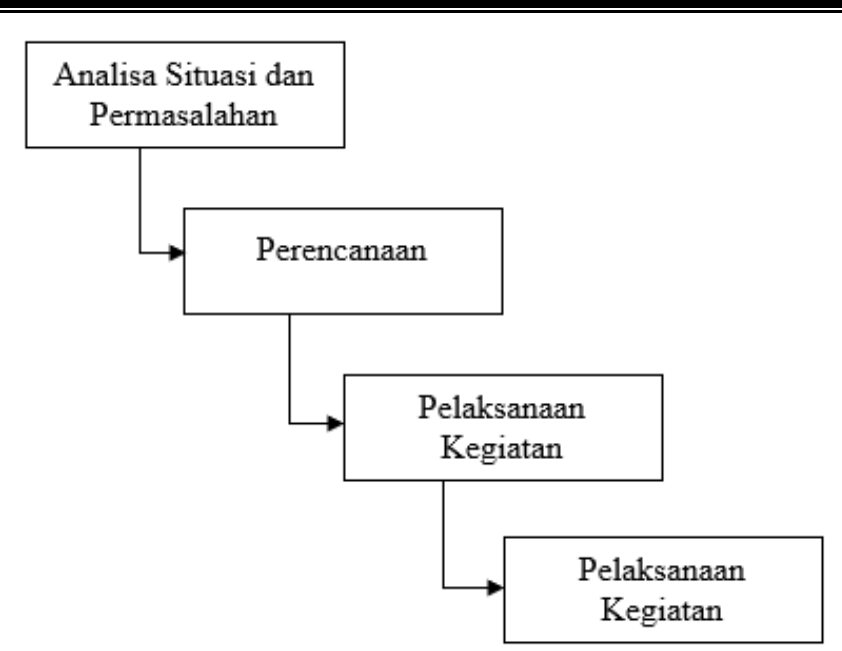

Gambar 1. Metode dan Tahapan Pelaksanaan Kegiatan

Deskripsi Metode dan tahapan pelaksanaan kegiatan:

a. Analisa Situasi dan Permasalahan

Dalam analisa situasi, tim pengabdian kepada masyarakat mengetahui tentang surat edaran Direktorat Jenderal Pembelajaran Dan Kemahasiswaan Nomor: B/565/B.B1/HK.01.01/2019 pada tanggal 8 Juli 2019 tentang Sarana Publikasi Karya Ilmiah Mahasiswa. Selanjutnya menganalisa masalah yang dihadapi mahasiswa STIE LMII yang akan melakukan publikasi artikel ilmiah hasil penelitian skripsi.

b. Perencanaan

Melakukan kordinasi dengan LPPM STMIK Pelita Nusantara dan Pihak STIE LMII. Selanjutnya mengajukan proposal pengabdian kepada masyrakat ke LPMM STMIK Pelita Nusantara.

c. Pelaksanaan

Melaksanakan pelatihan pembuatan artikel ilmiah dari hasil penelitian/skripsi mahasiswa dan pelatihan cara mempublish artikel ilmiah pada jurnal ilmiah.

d. Evaluasi

Kegiatan evaluasi dilakukan secara langsung oleh pelaksana pengabdian kepada masyarakat. Evaluasi berupa hasil kerja peserta yakni mahasiswa STIE LMII terkait pembuatan dan publikasi artikel ilmiah.

\section{HASIL DAN PEMBAHASAN}

Hasil pelaksanaan PkM yang sudah dilakukan, pertama TIM memberikan materi berupa surat edaran Direktorat Jenderal Pembelajaran Dan Kemahasiswaan Nomor : B/565/B.B1/HK.01.01/2019 pada tanggal 8 Juli 2019 tentang Sarana Publikasi Karya Ilmiah Mahasiswa.

Manfaat juga dijelaskan bahwa sangat penting menjadi bukti sahih penelitian mahasiswa bagi public melalui jurnal ilmiah. Setelah memahami manfaat besar dari upaya mengubah skripsi menjadi artikel ilmiah. Maka langkah selanjutnya adalah memahami tahapan atau tata caranya seperti apa. Sebab seperti yang diketahui, persyaratan untuk susunan skripsi akan berbeda dengan persyaratan dari penyusunan jurnal ilmiah. Untuk bisa mengubahnya dengan cepat atau efisien maka TIM menjelaskan trik khusus seperti berikut :

a. Menentukan Tujuan Jurnal

Tips pertama untuk mengubah skripsi menjadi sebuah jurnal ilmiah akan menentukan tujuan. Tujuan ini penting untuk ditentukan di awal karena akan mempengaruhi isi jurnal tersebut. Sekaligus mencari penerbit yang tepat. Tujuan yang tepat akan membantu proses publikasi jurnal ilmiah tersebut. Jadi, ada baiknya menentukan tujuan jurnal agar bisa sesuai dengan tujuan dari skripsi yang disusun. Setelah menentukan tujuan jurnal yang dituju sebagai 
tempat publikasi, mahasiswa juga dipermudah dengan mengikui template yang sudah disediakan jurnal tersebut.

b. Mengubah Pendahuluan Menjadi Abstrak

Secara umum mengubah skripsi menjadi artikel adalah tindakan yang banyak dilakukan penulis jurnal pemula. Sebab dengan mengandalkan hasil penelitian dari karya ilmiah tersebut, maka penyusunan jurnal ilmiah menjadi lebih mudah, tepat, dan juga cepat. Supaya maksimal dan tanpa kesalahan maka tips berikutnya untuk melakukan perubahan tersebut adalah mengubah Pendahuluan menjadi Abstrak. Baik Pendahuluan maupun Abstrak memiliki kesamaan. Biasanya abstrak mengandung semua elemen kunci untuk menarik minat dan perhatian dari pembaca. Berhubung Abstrak hanya terdiri dari 100 - 200 kata, maka perlu menyederhanakan bagian Pendahuluan. Sehingga penyusunan Abstrak tidak lagi memakan waktu lama.

c. Melakukan Modifikasi pada Pendahuluan

Pendahuluan di dalam jurnal ilmiah juga akan dibuat lebih singkat, maka perlu sedikit modifikasi dari Pendahuluan di skripsi. Caranya adalah memilih satu dari beberapa pertanyaan dan hipotesis di dalam Pendahuluan tugas akhir untuk dijadikan Pendahuluan dalam artikel ilmiah. Pertimbangkan juga untuk hanya menggunakan satu artikel saja. Sehingga isi dari Pendahuluan di dalam jurnal yang disusun sudah memenuhi kriteria dari artikel ilmiah secara umum.

d. Mempersingkat Penyusunan Skripsi

Saat berencana mengubah skripsi menjadi artikel maka penting sekali untuk menyusun kerangka tulisan. Kerangka ini bisa dimanfaatkan untuk pembuatan kerangka jurnal. Namun dengan dibuat lebih ringkas, sehingga ada beberapa bab di dalam tugas akhir yang bisa dihapus. Sehingga lewat kerangka tugas akhir tersebut bisa didapatkan kerangka untuk susunan jurnal ilmiah.

e. Memperbaiki Bagian Metode

Tips berikutnya untuk efisiensi dalam mengubah tugas akhir jenis apapun menjadi jurnal ilmiah adalah memperbaiki bagian metode. Ketika menyusun tugas akhir, sebut saja skripsi maka metode penelitian akan dijabarkan dengan sangat panjang dan lebar. Intinya sangat mendetail. Namun ketika diubah menjadi jurnal ilmiah maka penjabaran tersebut harus disederhanakan. Meskipun begitu tetap perlu dipastikan bahwa metode penelitian disampaikan dengan jelas.

f. Memuat Temuan Utama

Hasil penelitian tentu akan dipaparkan di dalam tugas akhir, dan bagian ini juga penting untuk dipaparkan di dalam bagian Pembahasan di jurnal ilmiah. Jadi khusus untuk bagian ini pastikan semua hasil temuan penelitian disebutkan dan dijabarkan. Sebab, hasil penemuan ini pada dasarnya adalah inti dari tugas akhir maupun jurnal ilmiah. Sehingga tidak perlu diutakatik kecuali jika hanya ingin sederhanakan agar jumlah halaman dari jurnal yang disusun tidak setebal tugas akhir.

g. Membatasi Referensi

Perbedaan persyaratan dalam tugas akhir dan jurnal ilmiah juga terletak pada referensi. Misalnya untuk kutipan yang dimasukan ke dalam bagian Pendahuluan maupun di bagian lain ketika diperlukan. Khusus untuk jurnal, referensi cenderung dibatasi dan dianjurkan untuk memilih referensi terbaru dan terkini. Sedangkan untuk tugas akhir biasanya bebas, selama lembaga atau institusi tempat peneliti bernaung tidak memberi batasan. Sebab beberapa perguruan tinggi membatasi referensi, misalnya saja hanya diperbolehkan mengambil referensi dari buku maupun jurnal yang terbit minimal 10 tahun yang lalu.

h. Diskusi Jelas dan Lengkap

Pada bagian Diskusi maka perlu ditulis atau disampaikan dengan jelas sekaligus lengkap. Inti dari penyusunan diskusi adalah mencoba memaparkan apa yang bisa didapat atau dipelajari oleh pembaca dari jurnal ilmiah yang disusun. Opsional lain adalah memaparkan 
hasil penemuan dari penelitian untuk dijadikan sebagai literatur. Bisa juga mendiskusikan hasil temuan tersebut untuk memperluas perspektif bidang yang dikaji. ini:

Dalam pelatihan untuk submite artikel kejurnal harus mengikuti Langkah-langkah berikut

a. Registrasi akun

Pada pelatihan submite artikel, tim menjelasksan cara melukan registrasi pada Journal of Economics and Business (JECOMBI) sebagai tempat publikasi. Pertama mahasiswa harus mengisi data-data yang diminta pada halaman registrasi, sampai registrasi berhasil.

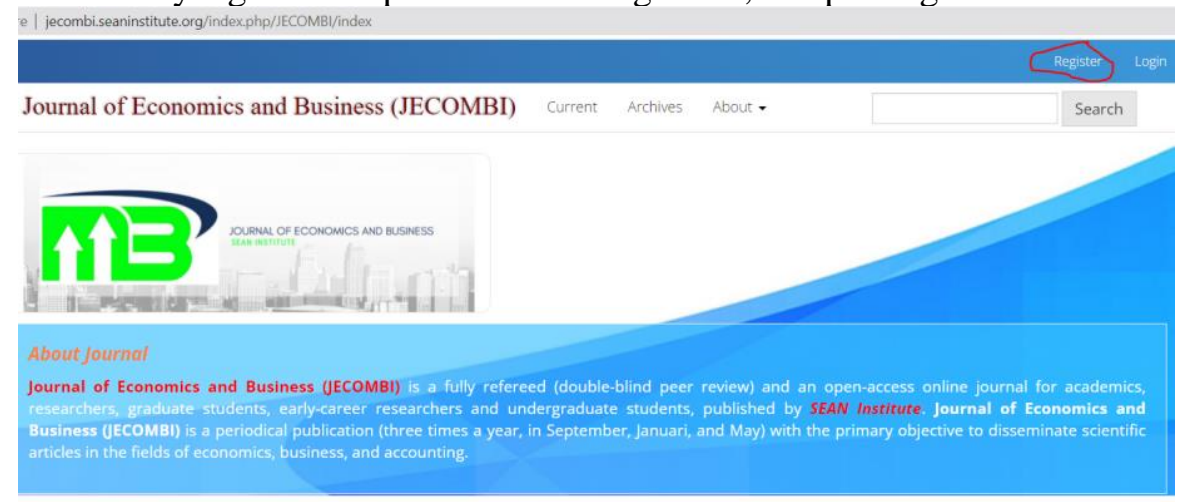

Gambar 1. Halaman registrasi

jecombi.seaninstitute.org/index.php/JECOMBI/user/register

Profile

Given Name *

Nera Mayana Br Tarigan

Family Name

Nera Mayana Br Tarigan

Affiliation *

STMIK Pelita Nusantara

Country*

Indonesia

Login

Email *

neramayana658@gmail.co

Username

nera

Password *

........

Repeat password²

.........

Yes, I agree to have my data collected and stored according to the privacy statement.

$\checkmark$ Yes, I would like to be notified of new publications and announcements

Would you be willing to review submissions to this journal?

$\varpi$ Yes, request the Reviewer role.

Register

Gambar 2. Halaman pengisian data profil

b. Melakukan submite artikel

Setelah registrasi akun berhasil, selanjutnya melukan submite artikel dari menu Make a New Submission, maka akan muncul seperti berikut: 


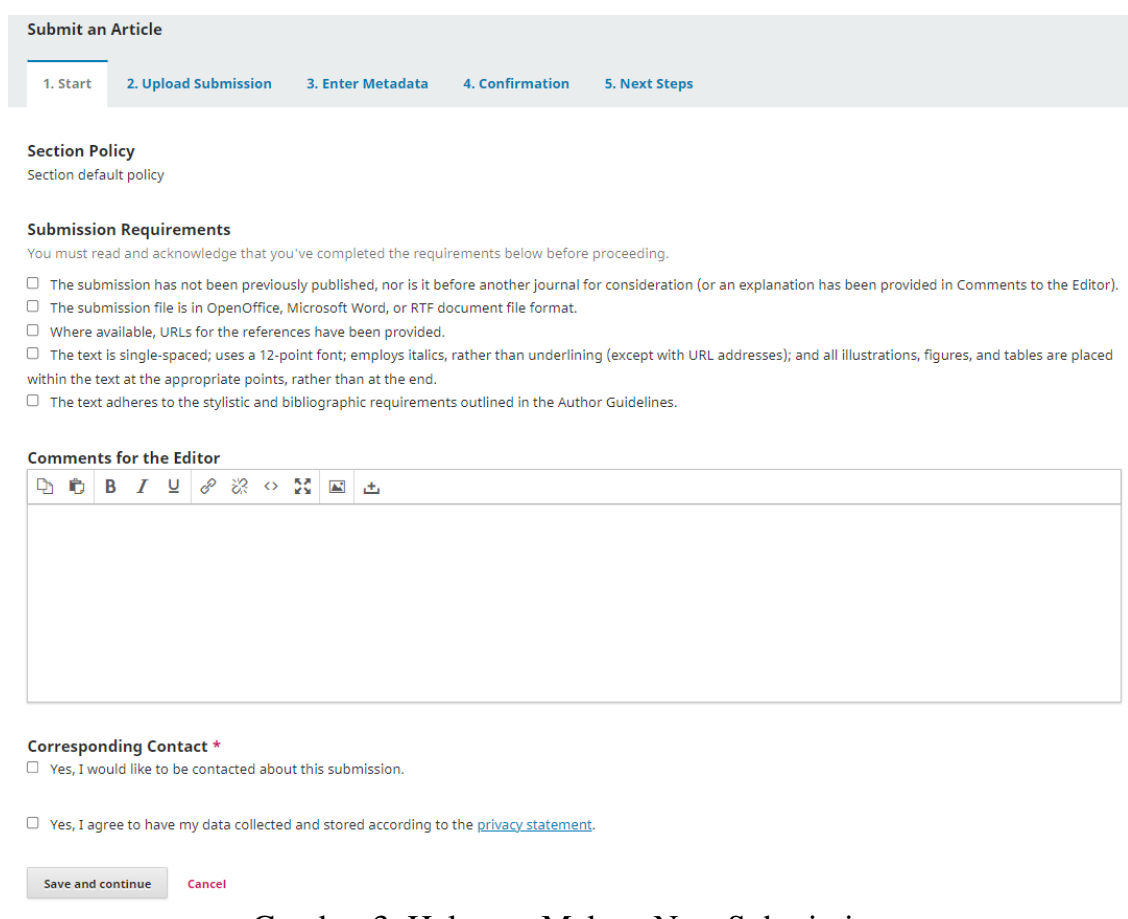

Gambar 3. Halaman Make a New Submission

Penulis diminta untuk melakukan pilihan, setelah dipilih tekan tombol save and continue. Makan akan masuk pada upload submission, disini akan diminta mengupload artikel yang sudah disusun. Sampai finis submission.

Setelah selesai pelaksanaan pelatihan, tim meberikan evaluasi terhadap kinerja tim PkM dengan meberikan kuesioner dengan penilaian sangat baik, baik, cukup baik, tidak baik, dan sangat tidak baik. Berikut hasil evaluasi yang diberikan:

Tabel 1. Contoh Penulisan Tabel

\begin{tabular}{|c|c|c|c|c|c|c|}
\hline No & Pertanyaan Kuesioner & $\begin{array}{l}\text { Sangat } \\
\text { Baik }\end{array}$ & Baik & $\begin{array}{l}\text { Cukup } \\
\text { Baik }\end{array}$ & $\begin{array}{l}\text { Tidak } \\
\text { Baik }\end{array}$ & $\begin{array}{l}\text { Sangat } \\
\text { Tidak } \\
\text { Baik }\end{array}$ \\
\hline 1. & Materi sesuai dengan permasalahan & $78,95 \%$ & $21,05 \%$ & $0,00 \%$ & $0,00 \%$ & $0,00 \%$ \\
\hline 2. & Contoh kasus yang diberikan & $73,68 \%$ & $15,79 \%$ & $10,53 \%$ & $0,00 \%$ & $0,00 \%$ \\
\hline 3. & Materi mudah dipahami & $73,68 \%$ & $26,32 \%$ & $0,00 \%$ & $0,00 \%$ & $0,00 \%$ \\
\hline 4. & $\begin{array}{l}\text { Materi meningkatkan } \quad \text { kemanpuan } \\
\text { mahasiswa }\end{array}$ & $84,21 \%$ & $15,79 \%$ & $0,00 \%$ & $0,00 \%$ & $0,00 \%$ \\
\hline 5. & Cara menjelaskan instruktur terhadap materi & $78,95 \%$ & $10,53 \%$ & $10,53 \%$ & $0,00 \%$ & $0,00 \%$ \\
\hline 6. & $\begin{array}{l}\text { Kemampuan instruktur dalam menjelaskan } \\
\text { materi }\end{array}$ & $63,16 \%$ & $31,58 \%$ & $5,26 \%$ & $0,00 \%$ & $0,00 \%$ \\
\hline 7. & $\begin{array}{l}\text { Cara instruktur dalam memberikan dan } \\
\text { menjawab pertanyaan }\end{array}$ & $68,42 \%$ & $26,32 \%$ & $5,26 \%$ & $0,00 \%$ & $0,00 \%$ \\
\hline 8. & $\begin{array}{l}\text { Kejalasan suara dan langkah-langkah yang } \\
\text { diberikan instruktur }\end{array}$ & $73,68 \%$ & $26,32 \%$ & $0,00 \%$ & $0,00 \%$ & $0,00 \%$ \\
\hline 9. & Metode pelatihan/studi kasus & $78,95 \%$ & $15,79 \%$ & $5,26 \%$ & $0,00 \%$ & $0,00 \%$ \\
\hline 10. & $\begin{array}{l}\text { Evaluasi terhadap kemampuan mahasiswa } \\
\text { sebelum dan sesudah pelatihan materi }\end{array}$ & $84,21 \%$ & $15,79 \%$ & $0,00 \%$ & $0,00 \%$ & $0,00 \%$ \\
\hline
\end{tabular}

\section{KESIMPULAN}

TIM pelaksana PkM menarik kesimpulan dari hasil pelaksanaan sampai saat ini yaitu :

a. Bahwa mahasiswa STIE LMII sangat tertarik dan yang mengikuti pelatihan sangat mudah mengikuti materi pelatihan 
b. Mahasiswa STIE LMII yang mengikuti pelatihan mampu membuat artike ilmiah dari hasil penelitian/skripsi.

\section{DAFTAR PUSTAKA}

Surat Edaran Direktorat Jenderal Pembelajaran Dan Kemahasiswaan Nomor: B/565/B.B1/HK.01.01/2019 pada tanggal 8 Juli 2019 tentang Sarana Publikasi Karya Ilmiah Mahasiswa.

Saukah, A. dkk. 2001. Pedoman Penulisan Karya Ilmiah (Ed.4th). Malang: Universitas Negeri Malang.

Sumartini, Mulyani, M., \& Nugroho, B. A. (2019). Workshop Penulisan Karya Ilmiah Bagi Guru. Jurnal Puruhita, 1(1), 54-59.

Widagdo, A. S. (2018). Pelatihan Penulisan Artikel Ilmiah Bagi Guru-guru SD Di Kecamatan Kendal. Abdimas Unwahas, 3(3), 25-29.

Hidayah, dkk. (2020). Pelatihan Penulisan Artikel Ilmiah Berbasis Penelitian Tindakan Kelas (PTK) Bagi Guru Kimia SMA di MGMP Kimia SMA Kabupaten Kediri. Jurnal ABDI. Vol.5No. 2Januari 2020, hal. 107-110. p-ISSN:2460-5514. e-ISSN: 2502-6518.

Marwoto, dkk. 2013. Peningkatan Kemampuan Menulis Artikel Ilmiah Sains Guru Sekolah Dasar Melalui Kegiatan Pengabdian Masyarakat. ABDIMAS Vol. 17 No. 2, Desember 2013.

Zulfadli Zulfadli, Ferryansyah Ferryansyah. (2017). PELATIHAN DAN BIMBINGAN PEMBUATAN KARYA TULIS ILMIAH BERBASIS PENELITIAN TINDAKAN KELAS (PTK) DI SD MUHAMMADIYAH 1 TARAKAN. JURNAL PENGABDIAN MASYARAKAT BORNEO. VOLUME 1 NOMOR 1 TAHUN 2017. Halaman 1-52. eISSN: 2579-9797.

Aina, M., Bambang, H.,Retni,S.S., Afreni, H.,\& Sadikin, A., (2015). Pelatihan Penulisan Karya ilmiah Bagi guru-guru sma 8 kota jambi. Jurnal pengabdian pada masyarakat,30 (3)

Noorjannah,L. (2014). Pengembangan profesionalisme Guru Melalui Penulisan karya tulis ilmiah bagi guru profesional di SMA Negeri 1 Kauman Kabupaten Tulungagung I Jurnal Humanity, 10 (1), 97-114

Zahro, Nur. (2019). PKM Pelatihan Penulisan Karya Tulis Ilmiah Bagi Guru Sekolah Dasar Kecamatan Situbondo di SD Islam Al Abror. Dedication : Jurnal Pengabdian Masyarakat. 3. 89-98. 10.31537/dedication.v3i2.236.

Hasmyati, Sarifin, Ricardo Valentino L. 2019. PKM penulisan karya ilmiah mahasiswa Fakultas Ilmu Keolahragaan Universitas Negeri Makassar. PROSIDING SEMINAR NASIONAL LEMBAGA PENELITIAN DAN PENGABDIAN KEPADA MASYARAKAT UNIVERSITAS NEGERI MAKASSAR. ISBN: 978-623-7496-01-4.

Prayitno Basuki, Thatok Asmony, Endar Pituringsih. 2018. Pelatihan Penulisan Karya Ilmiah Sebagai Syarat Kelulusan Bagi Mahasiswa Akuntansi Unit Program Belajar Jarak Jauh Di Mataram. Prosiding PKM-CSR, Vol. 1 (2018). e-ISSN: 2655-3570.

Sinaga, B., Hasugian, P. M., Manurung, J., \& Br.Tarigan, N. M. (2021). Pelatihan E-Promosi Kampus. Jurnal Pengabdian Kepada Masyarakat Nusantara, 2(1), 17-23. Retrieved from http://ejournal.sisfokomtek.org/index.php/jpkm/article/view/183 